\title{
A New Perspective: Investment and Efficiency under Incentive Regulation
}

\author{
Rahmatallah Poudineh* and Tooraj Jamasb**
}

\begin{abstract}
Following the liberalisation of the electricity industry since the early 1990s, many sector regulators have adopted incentive regulation aided by benchmarking and productivity analysis. This approach has often resulted in efficiency and quality of service improvement. However, there remains a growing concern as to whether the utilities invest sufficiently and efficiently in maintaining and modernising their networks. This paper studies the relationship between investments and cost efficiency in the context of incentive regulation with ex-post regulatory treatment of investments using a panel dataset of 129 Norwegian distribution companies from 2004 to 2010. We introduce the concept of "no impact efficiency" as a revenueneutral efficiency effect of investment under incentive regulation that makes a firm "investment efficient" in cost benchmarking. Also, we estimate the observed efficiency effect of investments and compare these with the no impact efficiency. Finally, we discuss the implications of cost benchmarking for investment behaviour of network companies.
\end{abstract}

Keywords: Investments, Cost efficiency, Incentive regulation, Distribution network, No impact efficiency

http://dx.doi.org/10.5547/01956574.36.4.rpou

\section{INTRODUCTION}

In recent years, achieving a sustainable electricity sector, security of supply, and reliability of service have emerged as overarching energy policy objectives in many countries. A sustainable energy economy is highly dependent on decarbonising the electricity sector. Meanwhile, further electrification of the energy is generally regarded as desirable for a sustainable energy-economy. These objectives are pursued through large scale deployment of renewable energy resources, more efficient use of energy, and active participation of the demand side.

Achieving the above goals requires a transformation of the electricity networks through expansion of grids, adoption of new technologies for managing the variability of the supply side, accommodating an active demand side, and focused research and development. Such transformation can only be reached through substantial capital investments. Given the anticipated scale of the required investments in the coming years, ensuring sufficient and efficient investments in the networks presents itself as a policy and regulatory priority.

* Durham University Business School, Now at "Oxford Institute for Energy Studies". Address: 57 Woodstock Road, Oxford, OX2 6FA, United Kingdom.

** Corresponding author. Durham University Business School, Mill Hill Lane, Durham DH1 3LB, United Kingdom, Phone: + 44 (0)191 33 45463, Email: tooraj.jamasb@durham.ac.uk.

The Energy Journal, Vol. 36, No. 4. This article is Gold Open Access and published under CC-BY license terms and conditions. 
Following the liberalisation of the electricity industry since the early 1990 s, many sector regulators have recognised the potential for cost efficiency improvement in the networks through incentive regulation aided by cost benchmarking and productivity analysis. Although benchmarking has achieved efficiency improvements (mainly in operating costs), new challenges have emerged as how to address the issue of network investments. The challenge is whether a regulatory scheme can be designed to provide the right incentives for the delivery of cost effective services while ensuring there is no systematic underinvestment or overinvestment. Hence, regulators need to balance the cost and risk of underinvestment against the cost of overinvestment in maintaining and modernising the networks.

Incentive regulation accentuates static cost efficiency while investment is a dynamic and long term activity. On the other hand, benchmarking is a relative concept in the sense that a firm's efficiency depends not only on its own performance but also on the performance of other companies. The paradoxical effect of incentive regulation concerning investment and the peculiar specifications of total cost benchmarking complicate the relationship between investment and cost efficiency under incentive regulation with the ex-post regulatory treatment of investments.

This paper analyses the relationship between cost efficiency and investments under incentive regulation with ex-post regulatory treatment of capital expenditure using the case of electricity distribution networks in Norway. The contribution of this paper is two-folded. Firstly, we introduce the concept of "no impact efficiency" as a revenue-neutral efficiency effect of investment under incentive regulation which makes the firm "investment efficient" and immune from cost disallowance in benchmarking process. Secondly, we estimate the "observed" efficiency effect of investment in order to compare this with no impact efficiency and discuss the implication of cost benchmarking for network investments in Norway. Despite the important role of regulatory treatment of capital expenditure, using benchmarking total costs, for investments behaviour and efficiency improvement in the networks, the topic has not been formally studied in the empirical literature.

The next section discusses the relationship between network investments and incentive regulation with reference to the Norwegian regulatory regime. Section 3 describes the methodology used to conceptualise the efficiency implications of investment under incentive regulation and also presents the stochastic frontier analysis procedure. The empirical results are presented and discussed in Section 4. Section 5 is the conclusions.

\section{INVESTMENT AND REGULATION}

Electricity network companies are regulated natural monopolies and hence, investments by these firms are not governed by market mechanisms where decisions are normally based upon expected higher returns than the cost of capital. In a regulated environment such as the electricity networks, the investment behaviour of firms is strongly influenced by their regulatory framework and institutional constraints (Vogelsang, 2002; Crew and Kleindorfer, 1996). The low-powered regulatory regimes such as pure "rate of return regulation" are often associated with poor incentive for efficiency. Averch-Johnson (1962) showed that regulated monopolies have an incentive to overinvest when the allowed rate of return is higher than the cost of capital.

Incentive-based regimes such as price or revenue caps aim to overcome the efficiency problem by decoupling prices from utilities' own costs. However, they also give rise to new challenges regarding the level of investments. The issue of cost efficiency at the expense of investments or service quality has been discussed in the literature (see e.g., Giannakis et al., 2005; Rovizzi and Thompson, 1995; Markou and Waddams Price, 1999). In addition, when rewards and penalties are weak or uncertain, the incentives for cost reductions outweigh the inducement to maintain quality 
of service and investment (Burn, and Riechmann, 2004). Furthermore, implementing incentive regulation is complicated and an evaluation of the associated efficiency is more difficult than it is often implied (Joskow, 2008).

The empirical evidence concerning investment behaviour of firms under incentive regime is not conclusive. While some initially argued that incentive regulation will lead to underinvestment, subsequent empirical works demonstrated that the outcome of the incentive regulation concerning the investment behaviour can be in either direction. Waddams Price et al. (2002), state that a highpowered incentive regulation might lead to overinvestment. Roques and Savva (2009) argue that a relatively high price cap can encourage investment in cost reduction as in an unregulated company. Nagel and Rammerstorfer (2008), on the other hand, show that a strict incentive regulation regime is more likely to create disincentive for investment. However, it is generally agreed that in incentive regulation regimes, due to the separation of firms' own cost from prices, the motivation for cost reducing investment is higher than under the rate of return regulation models (Ai and Sappington, 2002; Greenstein et al., 1995; Cambini and Rondi, 2010).

Thus, the main challenge of the regulator is to design the right incentives in order to prevent any systematic overcapitalisation or underinvestment. The ability to disallow excessive costs can help regulators achieve more efficient levels of investments which otherwise firms would tend to overinvest in risky projects (Lyon and Mayo, 2005). However, following periods of cost disallowances there is a greater possibility of disincentive for investments.

The regulatory opportunistic behaviour is also a concern for the regulated firms as this introduces uncertainty into the regulatory contract. Gal-Or and Spiro (1992), for example, argue that a sudden shift in the regulatory regime which allows for the use of cost disallowance instruments will decrease the propensity to invest. Thus, the presence of uncertainty in regulation influences investment behaviour of network companies. Under uncertainty, delaying investments may be beneficial even though a project may recover its capital costs (Dixit and Pindyck, 1994). There is also non-regulatory uncertainty, such as future demand, that the regulated company needs to take into consideration when deciding to invest.

From the regulatory viewpoint, it is important that decisions influencing the investment level of the firms are based upon economic efficiency. For example, the cost of reducing service interruptions through investments should be lower than the socio-economic costs of service interruption. In effect, the regulator seeks an efficient level of investment in the grid although realising this goal through regulation is a challenging task. On the one hand, theory does not provide clear indications of the conditions under which "efficient" levels of investment are achieved and which factors lead to over or underinvestment (von Hirschhausen, 2008). On the other hand, the empirical evidence from cases of overinvestment or underinvestment is rare. Therefore, the outcome of incentive regulation regarding investments is ambiguous, and that regulators, in practice, tend to adopt a combination of different incentive mechanisms in order to achieve their objectives.

\subsection{Power Sector Reform and Network Regulation in Norway}

Norway was among the first countries, after Chile and the UK, which embarked on power sector reform by unbundling the different elements of the electricity industry across the value chain. The generation and retail supply which are potentially competitive were separated from the transmission and distribution that are natural monopolies. Therefore, the distribution and transmission networks are subject to economic regulation. The Norwegian Water Resource and Energy Directorate (NVE) were appointed as the sector regulator since Norwegian Energy Act came into effect in 1991. Unlike the other countries where the regulatory reform was often accompanied by transfer 
of ownership, the Norwegian power industry mainly remained under the state or local municipalities' control after the reform. Also, companies that are involved in both monopolistic (distribution or regional transmission) and competitive businesses (generation or retail supply) are required to keep them separated legally and/or financially. ${ }^{1}$

In the early years of the reform, there were approximately 230 distribution networks and 70 generation units in Norway. The high number of utilities reflects the dispersed nature of the hydroelectric resources as the main source of power generation as well as the historical development of the sector in the country. In December 2010, around 167 companies were engaged in grid operation (NVE, 2010). The marked reduction in the number of distribution companies is the result of mergers and acquisitions among the network companies in pursuit of scale efficiency and other gains.

After the reform, initially, the distribution companies were operating under a rate of return regulatory regime. However, due to the lack of incentives for cost efficiency, since 1997, the regulatory regime was changed to incentive regulation. From 2007, NVE has implemented a new regulatory model which uses the Data Envelopment Analysis (DEA) as efficiency and cost benchmarking method. The networks companies are regulated with a revenue cap regime that covers their costs annually based on their distance from the efficient frontier (best practice) in the sector.

\subsection{Investments under Norwegian Regulatory Regime}

A feature of the Norwegian incentive regulation is to prevent systematic overinvestment or underinvestment in the networks. The incentives are provided through a combination of economic and direct regulation (NordREG, 2011). Along with profit motivation, the network companies need to undertake substantial investments in order to meet their obligations as stated in the Energy Act. For example, Section 3-4 of the amended Energy Act states that distribution companies are obliged to connect new generation sources and consumers that are not covered by the supply requirement.

Moreover, distribution companies are incentivised to maintain a high level of quality of service. The cost of network energy losses and cost of energy not supplied (CENS) due to interruptions or capacity constraints in the grid are incorporated in the regulatory model so that the firms take them into account. Therefore, firms normally should not have incentive to tune out their reinvestments as this would increase their total costs due to deterioration of their quality of service over time. In addition, a profit incentive is provided through a minimum guaranteed return on capital. The regulation states that all companies should achieve a reasonable (minimum 2\%) return on capital, given effective management, utilization, and development of the networks ${ }^{2}$. Similarly, overinvestment will increase the total costs and will negatively affect their relative efficiency in the cost benchmarking exercise which will impact their revenue adversely.

Figure 1 shows total investments, new investments, and reinvestments by the distribution companies between 2004 and 2010. As shown in the figure, total investments are strictly increasing since 2006. The investment data indicates that the source of the increase is the reinvestments and not the new investments. Although new investments remained almost constant, they have had a

1. In 2010, about 67 companies were involved in generation, grid operation, and supply to end users. Vertically integrated companies with more than 100,000 customers are obliged to separate their monopolistic operation from competitive activities (legal unbundling) (NVE, 2010). Also, the Energy Act requires the integrated companies to keep separate accounts for their monopoly and competitive businesses (NVE, 2010).

2. A network that falls below this minimum level will receive a correction in its revenue to achieve a minimum $2 \%$ return on capital. The normal rate of return for Norwegian distribution networks is currently $5.62 \%$. 


\section{Figure 1: Investments in Norwegian Distribution Companies}

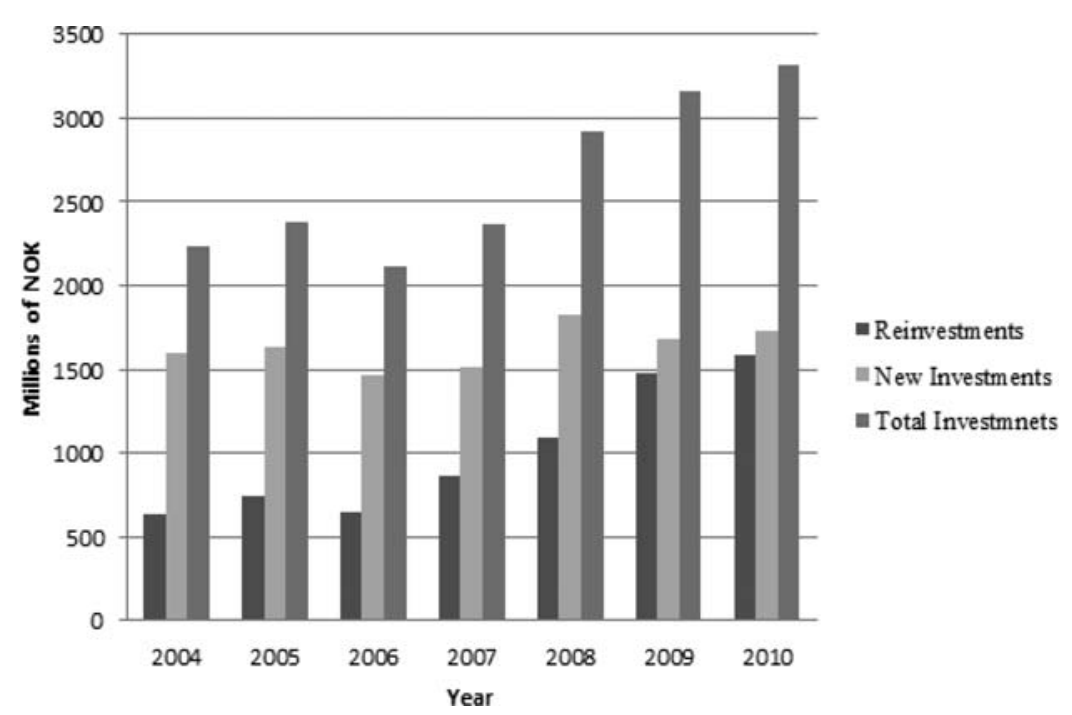

higher share in total investments than reinvestments. For instance, $68 \%$ of the investments observations, during the period of study, have a share of new investments to total investments higher than $50 \%$. This can be an indication of strong investment incentives which have motivated the networks to undertake new investments, possibly beyond their minimum reinvestment needs. Such a change can be attributed to the view that social costs of underinvestment are higher than social benefits of overinvestment (Helm and Thompson, 1991).

\section{METHODOLOGY}

In this section, we first present a model of the incentive regulation of electricity distribution networks in Norway and then analyse the relationship between investments by the utilities and the change in their relative efficiency under incentive scheme. We then describe the econometric approach and the models estimated in order to explore the efficiency effects of investments.

\subsection{Modelling Incentive Regulation}

The allowed revenues of regulated networks are determined by incentive regulation and cost efficiency benchmarking. Within this framework, investments are encumbered indirectly such that overinvestment can result in partial disallowance of investment costs. The Norwegian regulator computes the allowed revenue $\left(R E_{t}\right)$ of the networks using Equation (1), which, in essence, is a generic incentive regulation formula representing the trade-off between cost reduction incentive and rent transfer to the consumers, given the presence of asymmetric information between the firm and the regulator (Newbery, 2002; Joskow, 2005).

$$
R E_{t}=C_{t}+\lambda\left(C_{t}^{*}-C_{t}\right)
$$

Where $C_{t}$ is the actual (own) costs of a network company, $C_{t}^{*}$ is the norm cost obtained by using the frontier-based benchmarking method Data Envelopment Analysis (DEA), and $\lambda$ is the power 
of incentive in terms of the weight given to benchmarked costs vs. actual costs in setting the allowed revenue. The power of incentive is important for motivating the firms to move as close as possible to their norm (benchmarked) cost as they lose revenue when deviating from the efficient frontier. The share of actual costs and norm costs in determining the revenue caps is currently $40 \%$ and $60 \%$ respectively (i.e. $\lambda=0.6$ ) (NVE, 2008). Placing more weight on norm costs increases the incentive power of regulation and promotes indirect competition among the utilities to improve their cost efficiency relative to best practice.

Actual costs include operating and maintenance costs, capital costs, depreciation costs and cost of negative externalities such as network energy loss and service interruptions. In addition, the regulator deducts the cost of energy not supplied (CENS) from the firms' revenue cap ${ }^{3}$ and adjusts the allowed revenue for tax and other non-controllable expenses. The regulator uses data with a two year lag which is updated with an inflation index. The allowed revenue is then adjusted at the end of the year when final actual data becomes available. ${ }^{4}$

We divide both sides of (1) with $C_{t}$ and rearrange such that it yields:

$$
R E_{t}=C_{t}\left[1+\lambda\left(e_{t}-1\right)\right]
$$

where $e_{t}=\frac{C_{t}^{*}}{C_{t}}$ is the firms' efficiency in period $t$. When a firm invests the amount $I n$, this will impact its revenue by changing its relative efficiency in cost benchmarking. The variables for before and after undertaking investments are denoted by subscripts 1 and 2 respectively. The change in a firm's revenue due to an investment can be computed from equation (3).

$$
\Delta R E=R E_{2}-R E_{1}=C_{2}-C_{1}+\lambda\left[C_{2}\left(e_{2}-1\right)-C_{1}\left(e_{1}-1\right)\right]
$$

The change in actual cost of the firms after undertaking investments is equal to the amount of investments $\left(\Delta C=C_{2}-C_{1}=I n\right)$. We substitute for $C_{2}$ in the bracket and rearrange (3) as presented in (4) to show the change in revenue as a result of investments.

$$
\Delta R E=\Delta C+\lambda[\underbrace{C_{1}\left(e_{2}-e_{1}\right)+\operatorname{In} \times\left(e_{2}-1\right)}]
$$

Revenue effect of investments due to benchmarking

Equation (4) presents the main framework for the network companies' incentive to undertake investments. In the absence of cost benchmarking (i.e., when $\lambda=0$ ) the firm would automatically earn a return on its investments because the change in the firm's revenue is the same as the change in its cost $(\Delta R E=\Delta C)$, and the company can pass all its investment costs to its customers. However, as investments are included in cost benchmarking, the firms' revenue also depends on their relative cost efficiency before investments $\left(e_{1}\right)$ and after investments $\left(e_{2}\right)$. This is reflected in the second component of (4), to which we refer as $Q$ in (5), and shows the (gross) revenue effect of investments due to benchmarking.

3. In order to incentivise network companies to improve service quality (NVE, 2011).

4. While the current and previous year investments (years $t$ and $t-1$ ) are not included in the regulatory asset base (RAB) due to a time-lag, the companies can start to calculate a return on investment into their allowed revenue (i.e. tariff base) from the commissioning year. 


$$
Q=\left[C_{1}\left(e_{2}-e_{1}\right)+\operatorname{In} \times\left(e_{2}-1\right)\right]
$$

As seen from (5), the revenue effect of investments consists of two parts. Clearly, we always have $\left(e_{2}-1\right) \leq 0$. However, the outcome of the component $\left(e_{2}-e_{1}\right)$ of $(5)$ is not certain as it is not clear whether, following an investment, the cost efficiency increases, decreases, or remains constant. ${ }^{5}$

Depending on the initial and after investment measured cost efficiency, $Q$ can take different values. If $Q<0$, the firm gains less from investing compared to the case of no cost benchmarking (ceteris paribus). However, when $Q=0$ investment costs are fully recovered as there is no benchmarking. If $Q>0$, investment creates synergy by excessive increase in efficiency although this may not happen under normal condition ${ }^{6}$ so in most situations one expects $Q \leq 0$.

$$
\Delta R E=\Delta C+\lambda Q
$$

Thus, as shown in (6), the change in revenue after investments is not necessarily equal to the change in cost and it crucially depends on the value that $Q$ takes. Although the revenue also depends on the power of incentive $(\lambda)$, it is a predetermined parameter which is beyond the control of the firm. A desirable outcome can be achieved when $Q=0$ and benchmarking has no adverse impact on the firms' revenue.-i.e. when the efficiency after investments increases (due to productivity of capital) to an amount that results in $Q=0$ (note that also when the firm is on the efficient frontier and remains there after investments, we have $e_{2}=e_{1}=1$, and consequently $Q$ becomes zero). This efficiency can be obtained by solving (5) with respect to $e_{2}$ as in (7).

$$
e_{n o-i m p a c t}=e_{2}=\frac{C_{1} e_{1}+I n}{C_{1}+I n}
$$

Equation (7) shows how the Norwegian incentive regulation links investments to efficiency improvement. In order for a firm to earn a profit on its investments as if there was no cost benchmarking (ceteris paribus), its efficiency should be, at least, $\frac{C_{1} e_{1}+I n}{C_{1}+I n}$ after the investment. An efficiency level below this will result in lower revenue relative to the no benchmarking case. We use the term 'no impact efficiency' to refer to the revenue-neutral efficiency effect of investment under cost benchmarking as presented in (7). In other words, a firm is considered 'investment efficient' when it meets the 'no impact efficiency' criteria under regulation. ${ }^{7}$

The Norwegian incentive regulation links investment and efficiency to ensure that firms do not undertake undue investments. This means that the regulator does not need to interfere in the firms' investment decisions, but indirectly incentivises them to be investment efficient. A limit analysis of (7) shows that as $C_{1}$ increases, the efficiency $e_{2}$ will approach $e_{1}$. The opposite of this implies that when the ratio of investment to other $\operatorname{costs}^{8}$ increases, the firm needs to achieve a higher efficiency level (which in limits is equal to unity) in order to avoid revenue loss. This means

5. i.e. $\left(e_{2}-e_{1}>0, e_{2}-e_{1}<0\right.$ or $\left.e_{2}-e_{1}=0\right)$.

6. The reason is that if the share of investments to other costs (before investments) increases, the efficiency required to satisfy the inequality rises considerably. However, under certain circumstance we can have $Q>0$ which we refer to it in Section 4.

7. For simplicity, we assume that the frontier firms are genuinely efficient. In practice, this may not be the case.

8. The ratio of 'investment to other costs before investments', the average of this ratio for the Norwegian networks is currently $34 \%$. The maximum is $168 \%$ and the minimum is $0.1 \%$. 


\section{Figure 2: Possible Efficiency Effects of Investment under Norwegian Incentive Regulation}

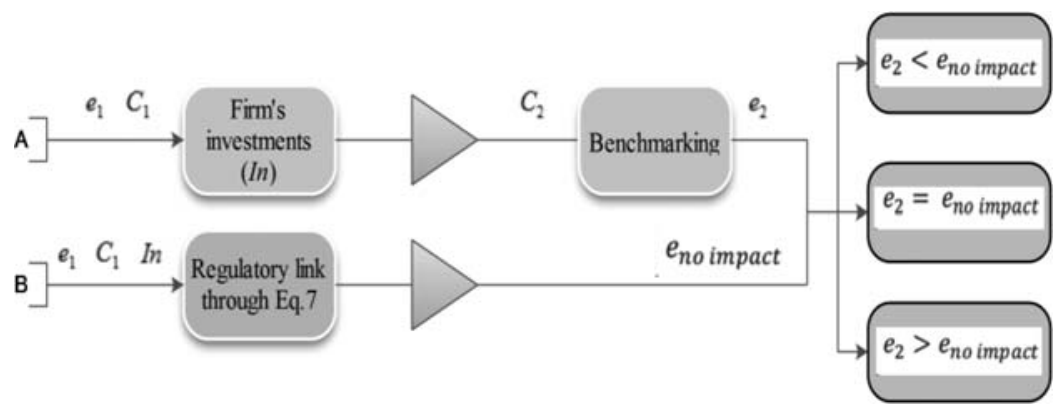

that the expected interval of the no impact efficiency change is $e_{1} \leq e_{\text {noimpact }} \leq 1$, which depending upon the investment to cost ratio would be closer to lower or upper boundary.

Figure 2 shows the possible outcomes of efficiency effect of investment under Norwegian regulation as an ex-post regulatory model for treatment of investments. When a firm (with an initial cost and efficiency level) undertakes an investment, it achieves a new level of efficiency (A). On the other hand, regulation links the initial cost, efficiency, and investment to no impact efficiency and rewards or penalises the firm based on the efficiency effect of their investments (B). In practice, this reflects the incentive mechanism pertaining to investments.

\subsection{Modelling a Stochastic Efficient Frontier}

This section presents the efficiency measurement techniques and empirical model estimated in this study. We estimate the efficiency of firms before and after investments and use the efficiencies to calculate the 'no impact efficiency' for current investment levels of the networks. We use an input distance function which allows us to estimate the efficiency of the firms when input price data is not available (Färe and Lovell, 1978; Coelli and Perelman 1996). Other advantages of distance functions are that they do not depend on explicit behavioural assumptions such as cost minimization or profit maximization and they can accommodate multiple inputs and outputs (Kumbhakar and Lovell 2000; Coelli et al., 2005).

Input distance functions have been used in empirical studies for efficiency and productivity analysis of industrial units as in Abrate and Erbetta (2010) and Das and Kumbhakar (2012) as well as those of electricity networks such as Tovar et al. (2011), Hess and Cullmann (2007), and Growitsch et al. (2012). The output of electricity networks is determined exogenously by demand for energy and connections. Thus companies can only adjust their inputs (i.e. costs) to deliver a given service efficiently.

An input distance function can be defined as in (8):

$$
D^{I}(x, y)=\max \left\{\psi:\left(\frac{x}{\psi}\right) \in L(y)\right\}
$$

where $L(y)$ represents the input vectors $x$ that produce the output vector $y$, and $\psi$ indicates a proportional reduction in input vector. The function has the following characteristics: (i) it is linearly homogenous in $x$, (ii) it is non-decreasing in $x$ and non-increasing in $y$, (iii) it is concave in $x$ and quasi-concave in $y$, and (iv) if $x \in L(y)$ then $D^{I} \geq 1$ and $D^{I}=1$ if $x$ is on the frontier of input set. 
Input-oriented technical efficiency is defined as the inverse of the distance function and can be obtained from (9).

$$
T E=1 / D^{I}(x, y), \quad 0<T E \leq 1
$$

When a firm is operating on the frontier it has a distance function value equal to unity and consequently has a technical efficiency score of 1 . We use a flexible functional form for input distance function as in (10):

$$
\begin{aligned}
\ln D_{i t}^{I} & =\alpha_{0}+\sum_{m=1}^{M} \alpha_{m} \ln y_{m i t}+\frac{1}{2} \sum_{m=1}^{M} \sum_{n=1}^{M} \alpha_{m n} \ln y_{m i t} \ln y_{n i t} \\
& +\sum_{k=1}^{K} \beta_{k} \ln x_{k i t}+\frac{1}{2} \sum_{k=1}^{K} \sum_{l=1}^{K} \beta_{k l} \ln x_{k i t} \ln x_{l i t} \\
& +\sum_{k=1}^{K} \sum_{m=1}^{M} \delta_{k m} \ln x_{k i t} \ln y_{m i t}+\theta_{1} t+\frac{1}{2} \theta_{11} t^{2}+v_{i t}
\end{aligned}
$$

where $D_{i t}^{I}$ represents the distance function, $y_{m i t}$ is output, $x_{k i t}$ is input, $t$ represents time trend, subscript $\mathrm{i}=1 \ldots \mathrm{N}$ denotes the number of the firms, and $\mathrm{t}=1 \ldots \mathrm{T}$ indicates number of years. Also, $m=1 \ldots M$ and $k=1 \ldots K$ show the number of outputs and inputs respectively. Parameters $\alpha, \beta$, $\delta$, and $\theta$ are to be estimated.

The flexible functional form relaxes the restrictions on demand elasticities and elasticities of substitution nevertheless; imposing appropriate curvature on translog models can be challenging (Greene, 2008). ${ }^{9}$ The time trend is included in order to capture technical change and also everything else that we cannot measure but varies over time and has a common effect on all firms (e.g., price of capitals, change in the regulatory environment, etc.).

The condition of homogeneity of degree one in inputs is imposed by the use of the following constraints: $\sum_{k=1}^{K} \beta_{k}=1$ and $\sum_{l=1}^{K} \beta_{k l}=0$ where $k=1,2, \ldots, K$ and $\sum_{l=1}^{K} \delta_{k m}=0$ where $m=$ $1,2, \ldots, M$.

The symmetry condition is met if:

$$
\begin{aligned}
\alpha_{m n} & =\alpha_{n m} \quad m, n=1,2, \ldots M, \quad \text { and } \\
\beta_{k l} & =\beta_{l k,} \quad k, l=1,2, \ldots, K
\end{aligned}
$$

We transform the input distance function into econometric models to be estimated by the stochastic frontier analysis (SFA) method and to obtain technical efficiency of the firms. Imposing the homogeneity of degree one by deflating $K-1$ inputs by $K$ th input (we use other cost $\left(C_{1}\right)$ to deflate) will lead to (12):

$$
\ln D_{i t}^{I}-\ln x_{K i t}=f\left[\left(\ln x_{k i t}-\ln x_{K i t}\right), \ln y_{m i t}, t\right]+v_{i t}
$$


where $f($.$) is the translog functional form. For the purpose of estimation we rearrange the above$ equation as:

$$
-\ln x_{K i t}=f\left[\left(\ln x_{k i t}-\ln x_{K i t}\right), \ln y_{m i t}, t\right]+v_{i t}-u_{i t}
$$

where $\ln D_{i t}^{I}=u_{i t}$ represents the non-negative technical inefficiency. The error components have the following distributions.

$$
\begin{aligned}
& v_{i t} \sim \operatorname{iid} N\left(0, \sigma_{v}^{2}\right) \quad \text { and } \\
& u_{i t} \sim i i d N^{+}\left(0, \sigma_{u}^{2}\right)
\end{aligned}
$$

where $v_{i t}$ is a normally distributed random error term and $u_{i t}$ is a half-normal heteroscedastic random error term that captures inefficiency. As the efficiency is affected by the investments we model the heteroscedastic inefficiency variance $\left(\sigma_{u}^{2}\right.$ het $)$ as in (15).

$$
\begin{aligned}
& \log \sigma_{u}^{2} \text { het }=\rho_{0}+\rho_{1} \log (\text { In })+\rho_{2} \log ^{2}(\text { In }) \\
& \sigma_{u}^{2} \text { het }=\exp \left(\rho_{0}+\rho_{1} \log (\operatorname{In})+\rho_{2} \log ^{2}(\text { In })\right)
\end{aligned}
$$

where $\rho_{0}, \rho_{1}$ and $\rho_{2}$ are parameters that need to be estimated and "In" is normalised investment level with respect to sample mean. As shown in (16) we can separate the heteroscedastic variance into its homoscedastic component $\left(\sigma_{u}^{2}\right.$ hom $)$ and the element related to investments.

$$
\begin{aligned}
& \sigma_{u}^{2 h e t}=\exp \left(\rho_{0}\right) \exp \left(\rho_{1} \log (\operatorname{In})+\rho_{2} \log ^{2}(\text { In })\right)= \\
& \sigma_{u}^{2 \text { hom }} \times \exp \left(\rho_{1} \log (\operatorname{In})+\rho_{2} \log ^{2}(\text { In })\right)
\end{aligned}
$$

This allows us to purge the effect of investments on inefficiency as seen from (17). In terms of estimation, equations (13) and (15) are estimated simultaneously based on the only observed data in (13). Having estimated them, the homoscedastic inefficiency can be obtained as follows:

$$
\begin{gathered}
u_{i t} \sim N^{+}\left(0, \sigma_{u}^{2} \text { hom } \times \exp \left(\rho_{1} \log (\operatorname{In})+\rho_{2} \log ^{2}(\text { In })\right)\right) \\
u_{i t} \sim N^{+}\left(0, \sigma_{u}^{2} \text { hom }\right) \times \exp \left(\rho_{1} \log (\operatorname{In})+\rho_{2} \log ^{2}(\text { In })\right) \\
\hat{u}_{i t}=\exp \left(\hat{\rho}_{1} \log (\operatorname{In})+\hat{\rho}_{2} \log ^{2}(\text { In })\right) \times \hat{u}_{\text {before }}
\end{gathered}
$$

It is clear that $\hat{u}_{i t}=E\left[u_{i t} \mid \epsilon_{i t}\right]$ where $\epsilon_{i t}=v_{i t}-u_{i t}$, On the other hand, $\hat{u}_{i t}=\hat{u}_{\text {after }}$ thus we can write:

$$
\hat{u}_{\text {before }}=\frac{\hat{u}_{\text {after }}}{\exp \left(\hat{\rho}_{1} \log (\operatorname{In})+\hat{\rho}_{2} \log ^{2}(\operatorname{In})\right)}
$$

where, $\hat{u}_{\text {before }}$ is before-investment inefficiency and $\hat{u}_{\text {after }}$ is after-investment inefficiency $\left(\hat{u}_{i t}\right)$. The firm specific technical efficiency is then computed by $e_{1}=\exp \left(-\hat{u}_{\text {before }}\right)$ and $e_{2}=\exp \left(-\hat{u}_{\text {after }}\right)$. The "no impact efficiency" is calculated using Equation (7). 


\subsection{Data}

We use a dataset comprising a weakly balanced panel of 129 distribution network utilities from 2004 to 2010. All monetary data are in real terms and adjusted to 2010 price level. The data is collected by the Norwegian Water Resource and Energy Directorate (NVE) and used in order to set the networks' allowed revenues. The data collection procedure is mainly through an electronic system named eRapp (NVE, 2007). These include both technical and economic data. The economic data gives detailed information on the costs and revenues with respect to different network activities. The technical data, on the other hand, include consumer specific information such as customer numbers at each category, energy distributed, network energy losses, and also technical information about the networks such as length, type and capacity of lines and cables, transformers, switches, number of meters and finally duration and frequency of interruptions (NVE, 2007).

The network companies are responsible for the accuracy of metering data within their grid area even for metering and collections that are outsourced to a third party. The only data that is not based on the firm's own report is the environmental data (see Footnote 12). Following the data collection, the economic data are verified by independent auditors and controlled by the regulator. Moreover, NVE controls the technical data by visiting the site and also auditing the technical components of distribution networks and other comparable sources (NVE, 2007).

Our distance function model consists of two inputs and two outputs. The inputs are capital expenditure $(I n)$ and other costs $\left(C_{1}\right)$. Following the Norwegian regulatory approach, we incorporate quality of service into our benchmarking model by adding the cost of negative externalities (network energy losses and service interruptions) to the directly incurred elements of operating cost as presented in (19).

$$
C_{1}=\text { Operational Expenditure }+ \text { Cost of Losses }+ \text { Cost of Energy Not Supplied }
$$

The cost of energy not supplied is calculated from the number of minutes of interruptions multiplied by consumer willingness-to-pay for a more reliable service. ${ }^{10}$ The cost of network energy losses is computed by multiplying the physical losses with average annual system price of electricity.

The standard outputs, in efficiency measurement of distribution companies, are the number of customers, energy distributed and network length (or the size of service area) (Coelli et al., 2012). We use "total number of customers" (residential plus recreational homes) and "network length as outputs. ${ }^{11}$ These two variables are commonly used in efficiency analysis of electricity networks (e.g., Growitsch et al., 2012; Miguéis et al., 2011; Coelli et al., 2012). In addition to the input and output variables we use three weather and geographical variables in order to capture the heterogeneity among firms. ${ }^{12}$ These factors can impact cost efficiency of the networks and controlling for

10. Consumer willingness to pay for quality of service is derived from consumer surveys and technical analysis.

11. We examined the case of using "distributed energy" as an output along with number of customers. However, due to the presence of sever multicollinearity between these two variables, the estimated function does not satisfy regularity conditions (i.e. monotonicity and concavity). This is also the case when we estimated with three standard outputs.

12. The three environmental variables are: (1) snow conditions, in millimeters of snow per year at a given temperature (around 0 degrees C), (2) Wind and distance to coast, as a ratio (average extreme wind/distance to coast), and (3) forest productivity, a number between 0 and 1 showing the share of forest with this growth rate along the power lines. 
Table 1: Descriptive Statistics

\begin{tabular}{|c|c|c|c|c|c|}
\hline Variable Description & Name & Min. & Max. & Mean & Std. Dev. \\
\hline \multicolumn{6}{|l|}{ Inputs } \\
\hline Other costs* & $C_{1}$ & 1205.25 & 1178987 & 41260.63 & 67709.02 \\
\hline Capital expenditures* & In & 6.82083 & 121042.4 & 13113.12 & 17518.02 \\
\hline \multicolumn{6}{|l|}{ Outputs } \\
\hline Network length $(\mathrm{Km})$ & $N L$ & 14 & 8111 & 558.27 & 779.13 \\
\hline Number of customers (\#) & $C U$ & 18 & 515152 & 13054 & 26964 \\
\hline \multicolumn{6}{|l|}{ Geographical variables } \\
\hline Snow condition (millimetres) & snow & 0 & 1193.61 & 372.64 & 196.54 \\
\hline Wind/distance to cost (ratio) & wind & 0 & 0.1610 & 0.0164 & 0.0289 \\
\hline Forest productivity (fraction) & forest & 0 & 0.5489 & 0.1566 & 0.1197 \\
\hline
\end{tabular}

*Monetary variables are in '000 NOK.

their effects can help to account for the heterogeneity in the operating environment of network companies (Jamasb et al., 2012). ${ }^{13}$ Table 1 summarises the descriptive statistics of the data used.

As we use "other costs" $\left(C_{1}\right)$ to impose homogeneity of degree one, the dependent variable of model is $-\log \left(C_{1}\right)$. The parameters used in the model are obtained by maximum likelihood estimation procedure. The optimisation technique used is Berndt-Hall-Hall-Hausman (bhhh) algorithm. Furthermore, in order to facilitate the interpretation of the first order terms, all variables are divided by their sample mean prior to estimation.

\section{RESULTS AND DISCUSSION}

The profit motive implies that incentive regulated firms evaluate the costs and benefits of undertaking investments by comparing the possible reductions and increases in their allowed revenue as a result of efficiency effect of their investments in cost benchmarking. However, the outcome depends on the net efficiency effect achieved by the investments.

Table 2 presents the results of the input distance function and heteroscedastic variance model estimations. As shown in the table, the coefficients of first order terms for the number of customers, network length and investments are statistically significant and have the expected signs. These coefficients can be interpreted as distance function elasticity with respect to outputs and inputs at sample mean. The first order coefficients for snow, wind and forest are significant and consistent in terms of sign indicating that these geographic variables are also cost drivers. Additionally, all interactions of the forest variable with outputs are significant. However, only one interaction term of wind and snow variables with outputs is statistically significant. The heteroscedastic inefficiency variance model shows significant coefficients both for the first order and quadratic terms.

The translog functional forms do not satisfy monotonicity and convexity globally (regularity conditions) hence, these need to be verified a posteriori (Sauer et al., 2006). Monotonicity implies two conditions for partial derivatives of input distance functions: non-decreasing in inputs and non-increasing in outputs (Perelman and Santin, 2005). Appropriate curvature implies concavity

13. We examined the influence of asset age (ratio of depreciation to book value) as a control variable. However, the variable showed inconsistencies in the sign of the age variable itself as well as for first order terms of other variables. Other measures of age may produce different results but these were not available. At the same time, the results indicated that inclusion of age does not change the efficiency scores significantly. 
Table 2: Input Distance Function Model Estimation

\begin{tabular}{|c|c|c|}
\hline \multicolumn{3}{|c|}{ Dependent variable: $-\log \left(C_{1}\right)$} \\
\hline Variables & Coefficient & Std. Err \\
\hline Constant & $-5.799 * * *$ & $(0.911)$ \\
\hline $\log (C U)$ & $0.428^{*}$ & $(0.233)$ \\
\hline $\log (N L)$ & $0.625 * * *$ & $(0.218)$ \\
\hline $\log (\operatorname{In})$ & $-0.924 * * *$ & $(0.170)$ \\
\hline $0.5 \log ^{2}(C U)$ & $0.235^{* * *} *$ & $(0.025)$ \\
\hline $0.5 \log ^{2}(N L)$ & $0.134 * * *$ & $(0.049)$ \\
\hline $0.5 \log ^{2}(\operatorname{In})$ & $-0.073 * * *$ & $(0.016)$ \\
\hline $\log (C U) * \log (N L)$ & $-0.159 * * *$ & $(0.036)$ \\
\hline $\log (C U) * \log (\operatorname{In})$ & -0.007 & $(0.020)$ \\
\hline $\log (N L) * \log (\operatorname{In})$ & 0.026 & $(0.020)$ \\
\hline$t$ & -0.010 & $(0.010)$ \\
\hline $0.5 t^{2}$ & $0.011 * * *$ & $(0.003)$ \\
\hline snow & $0.075 * * *$ & $(0.021)$ \\
\hline wind & $0.022 * * *$ & $(0.005)$ \\
\hline forest & $0.064 * * *$ & $(0.013)$ \\
\hline snow $* \log (C U)$ & -0.003 & $(0.029)$ \\
\hline snow $* \log (N L)$ & $0.073 * *$ & $(0.035)$ \\
\hline wind $* \log (C U)$ & $-0.019 * *$ & $(0.008)$ \\
\hline wind $* \log (N L)$ & 0.014 & $(0.009)$ \\
\hline forest $* \log (C U)$ & $0.077 * * *$ & $(0.023)$ \\
\hline forest $* \log (N L)$ & $-0.067 * * *$ & $(0.024)$ \\
\hline \multicolumn{3}{|c|}{$\log \left(\sigma_{u}^{2}\right)$} \\
\hline $\log (\operatorname{In})$ & $-1.801 * * *$ & $(0.684)$ \\
\hline $\log ^{2}(I n)$ & $-0.261 * *$ & $(0.124)$ \\
\hline Constant & $-5.605 * * *$ & (1.005) \\
\hline
\end{tabular}

Note: $* p<0.10 ; * * p<0.05 ; * * * p<0.01$

For ease of interpretation, the model coefficients were multiplied by -1 .

in inputs and quasi-concavity in outputs which boils down to a negative definite Hessian matrix on inputs and a negative semi-definite bordered Hessian matrix on outputs (Perelman and Santin, 2005). The results of a posteriori check on monotonicity and concavity conditions are presented in Tables $\mathrm{A} 1$ and $\mathrm{A} 2$ respectively.

The results show that monotonicity is satisfied at sample mean for all inputs and outputs. Moreover, for the inputs "investment" and "other costs" and output "network length" monotonicity is satisfied $100 \%$ over all data points. The figure is $99.6 \%$ for the other output "number of customers". The Hessian matrix of inputs is negative definite at sample mean without violation of appropriate curvature over data points. The bordered Hessian matrix of outputs is, however, indefinite at the point of approximation and satisfies appropriate curvature only $18.7 \%$ of times over data points. ${ }^{14}$

Figure 3 illustrates the changes in the efficiencies before and after investments. As shown in the figure, investments have impacted the efficiency of the networks and within a relatively wide

14. Appropriate curvature cannot be guaranteed at all data points due to the presence of trade-off between flexibility and theoretical consistency. It is, however, desirable to have these conditions at least at the vicinity of the approximation point (e.g., sample mean), or for a range of dataset in which case interpretation capabilities with respect to the data points far from point of approximation is restricted. For a detail discussion of the regularity conditions see Sauer et al. (2006). 
Figure 3: Efficiency Change Following Investments

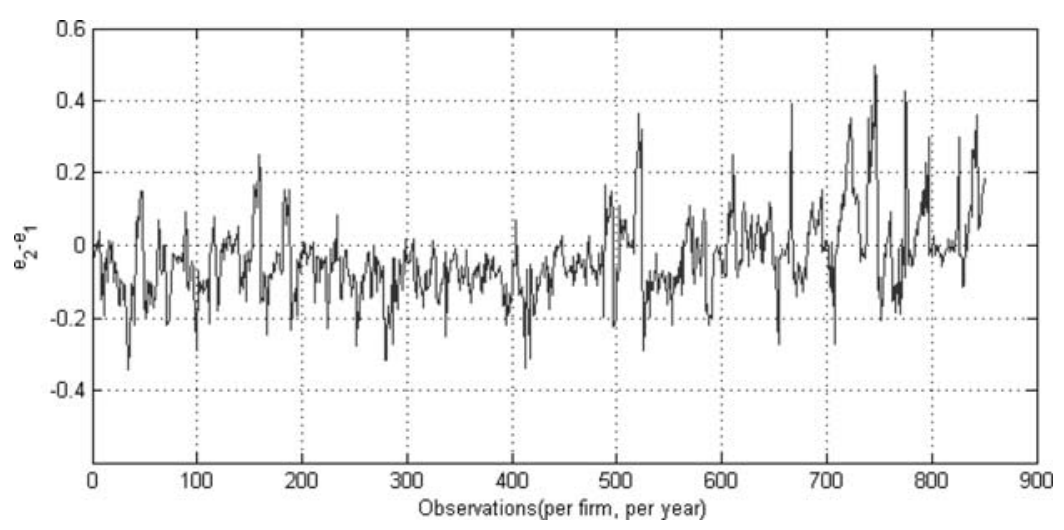

Figure 4: The Distribution of Efficiency Change Following Investments

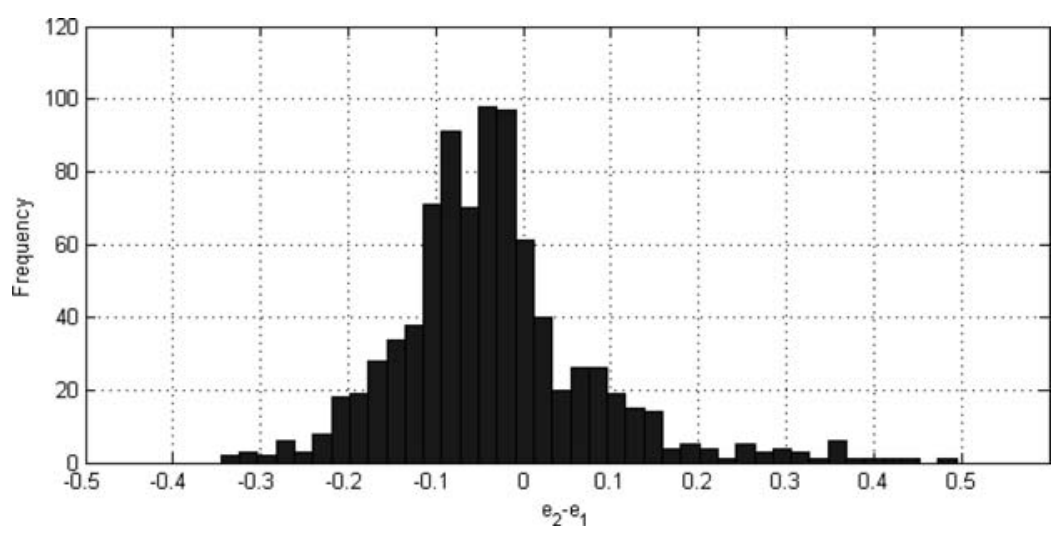

range. It is evident that the impact of investments on the efficiency variation among the firms is not uniform, in the sense that some of the firms have gained while some others lost efficiency. This complies with the basic notion of ex-post regulatory treatment of investments based on benchmarking that efficiency effects influence investment behaviour of firms as undue investments face the risk of efficiency loss.

Figure 4 shows the distribution of efficiency variation following investments. The descriptive statistics of graph data is presented in Table 3. As seen from the graph and the table, the change in efficiency tends towards an asymmetrical distribution. The Jarque-Bera test of normality is rejected and distribution is right skewed. The maximum positive variation is 0.49 whereas on the negative side it is -0.34 . Also, the majority of observations lie between -0.15 and 0.08 efficiency variations following investments (one standard deviation with respect to mean).

Furthermore, as illustrated by the scatter plot in Figure 5, efficiency loss after investments is more prevalent among the companies with lower investment to total cost ratios. On the other hand, companies with average investment levels show more efficiency gain following their investments compared with companies with very high share of investment in total cost. This suggests that middle scale investments have generally been more productive than the larger and especially than the small ones. 
Table 3: Descriptive Statistics

\begin{tabular}{lr}
\multicolumn{2}{c}{ of $\boldsymbol{e}_{\mathbf{2}}-\boldsymbol{e}_{\mathbf{1}}$} \\
\hline Mean & -0.035 \\
Median & -0.043 \\
Maximum & 0.496 \\
Minimum & -0.345 \\
Std. Dev. & 0.112 \\
Skewness & 1.022 \\
Kurtosis & 5.711 \\
Jarque-Bera & 408.59 \\
Probability & 0.000 \\
\hline
\end{tabular}

Figure 5: Efficiency Change Versus Investments to Total Cost Ratio

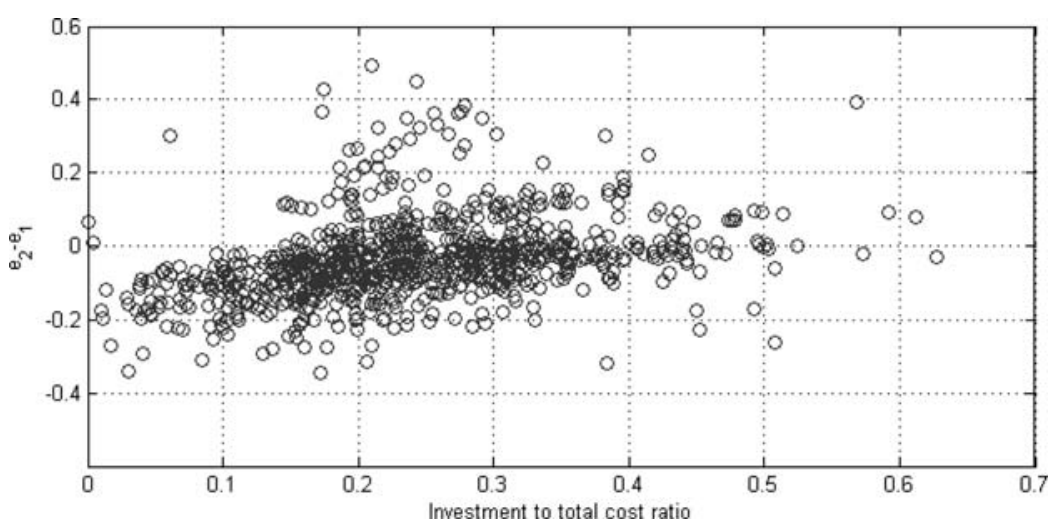

Figure 6: Efficiency Variation Versus Network Size (length)

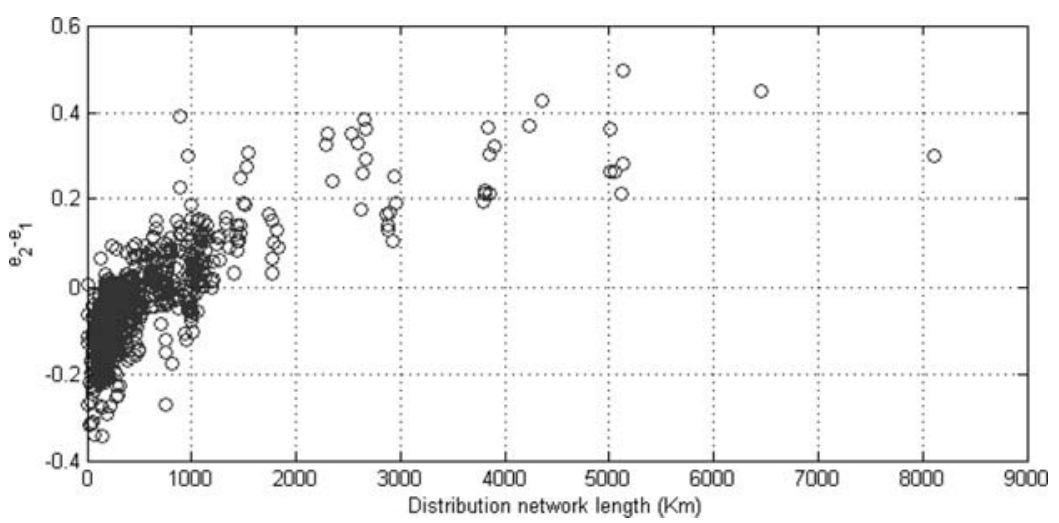

One striking point is that the efficiency loss following investment is mainly related to the smaller companies. As seen from Figure 6, many of the utilities with a network length of less than $1000 \mathrm{~km}$ have lost efficiency following their investments. These companies have also lower investment to total cost ratios. On the contrary, the efficiency gain from investments increases with the size of firm, in the sense that highest efficiency gains are achieved by firms with a network 
length in excess of $1000 \mathrm{~km}$. However, for very large firms, the efficiency gains from investments tend to decline again.

These observations suggest that smaller companies tend to be less productive and less able to absorb the full benefits of their capital expenditures. One reason can be that small companies are not operating at optimum size. ${ }^{15}$ Moreover, the fact that lower investment to total cost ratio in these companies did not lead to an efficiency improvement indicates the complexity of the investment and efficiency relationship under benchmarking as lower investment levels might lead to an increase in other costs and may not help with efficiency improvement. This also implies that small scale investments may need better scrutiny prior to implementation in order to avoid lower allowed revenues as a result of cost benchmarking.

Figure 7 summarises the distribution of before investment, after investment and no impact efficiencies estimated in different years. As seen from the figure, in all cases, the distributions do not show zero skewness rather the mass of distribution is concentrated around the more efficient region without a noticeable change over different years. Additionally, the lower quartile is higher for the case of no impact efficiency compared with before investments and after investments efficiency, suggesting that given the current levels of investment efficiency improvement is required for many firms.

Table 4 compares the average of the same efficiencies in each year for all companies. As the table shows, the average efficiency declined following investments and it falls behind no impact efficiency in all years. This deviation varies from $3.7 \%$ to $6.2 \%$ in different years. Moreover, there is no stable pattern of change, in average efficiencies, over different years. However, the average becomes affected with outliers hence; in order to make a more reliable inference on the performance of sector we have weighted the efficiencies by the share of their corresponding investment in the total investment of the sector. This is to ensure that the weight effect of firms on total investment in the sector is taken into account when looking at the sector level. This is particularly relevant to the case of the Norwegian distribution companies which are diverse in terms of network size and customer density.

As shown in Table 4, the average efficiency gain following investments increased to around $10 \%$ when weighted. Additionally, there is a decline in weighted no impact efficiency. Also, the weighted average efficiency following investment exceeds the no impact efficiency by around $6.4 \%$. This clearly indicates that equal treatment of firms to infer about their investment behaviour "at sector level" can result in biased conclusions. Moreover, the fact that the weighted average no impact efficiency declined below the weighted average after investment efficiency signals that the sector can still increase the level of investments, through new reallocation of investments, and without lowering the average efficiency gain of the sector.

The reallocation of investments can increase the total investments in the sector because there are significant performance differences among the companies as depicted in Figures 3 and 4. The very efficient utilities that exceeded the no impact efficiency may wish to increase their investment in order to gain from their efficiency level. The investment increase can be continued until efficiency after investment declines to no impact efficiency, in which state, a form of optimality is achieved. On the other hand, those firms that their efficiency after investments falls short of no impact efficiency need to reduce their investment level in order to avoid inefficiency associated

15. In the extreme, one network served 18 customers in a year and one with $14 \mathrm{Km}$ of network length only (see Table 1). As seen from Figure 6, the majority of the companies have a network length of less than $1000 \mathrm{Km}$. 


\section{Figure 7: Distribution of Efficiencies Estimated}
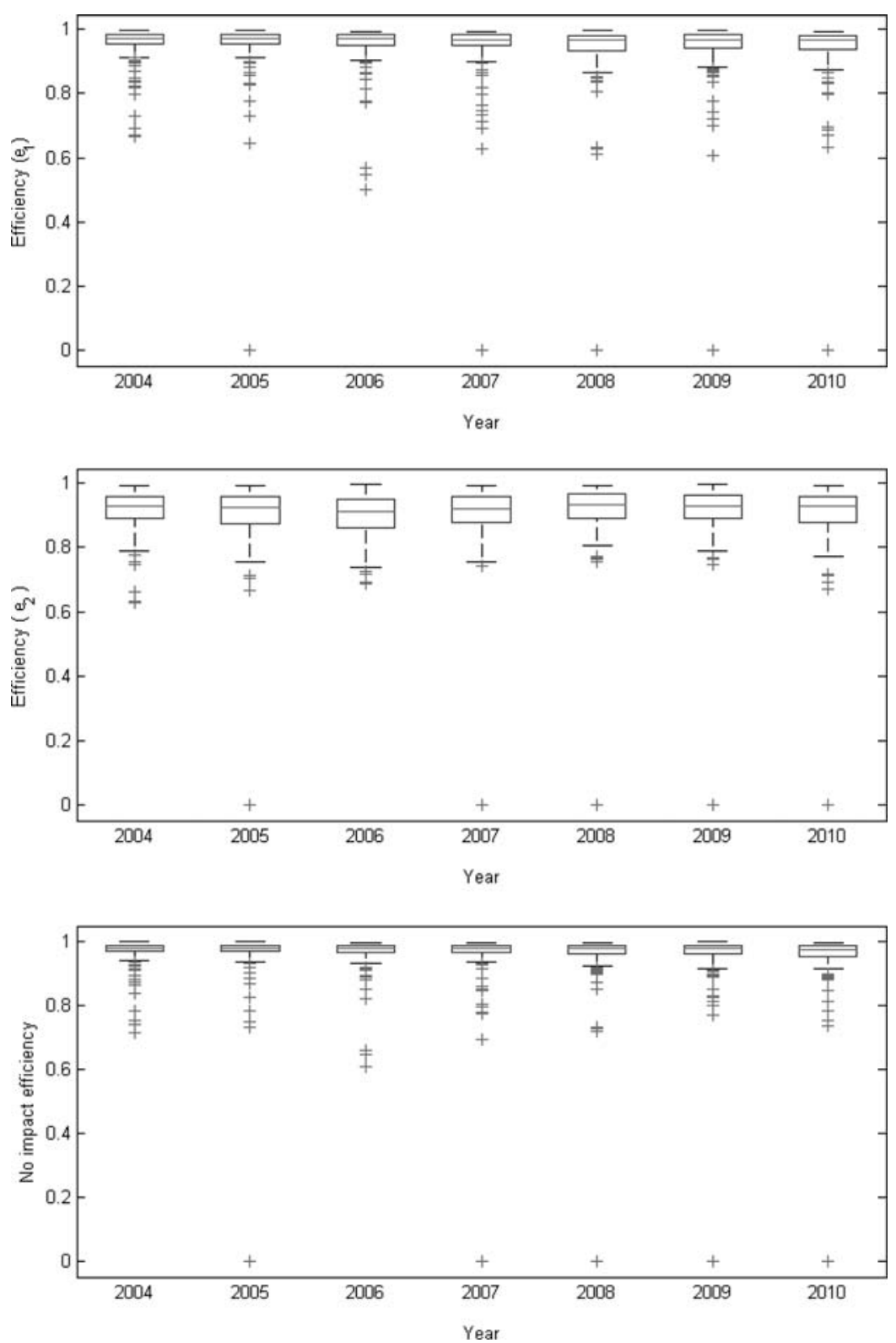

Table 4: Average "Before Investment," "After Investment," and "No Impact" Efficiency

\begin{tabular}{lccccccc}
\hline Efficiency measured & $\mathbf{2 0 0 4}$ & $\mathbf{2 0 0 5}$ & $\mathbf{2 0 0 6}$ & $\mathbf{2 0 0 7}$ & $\mathbf{2 0 0 8}$ & $\mathbf{2 0 0 9}$ & $\mathbf{2 0 1 0}$ \\
\hline Average of $e_{1}$ & 0.951 & 0.953 & 0.948 & 0.949 & 0.947 & 0.946 & 0.943 \\
Average of $e_{2}$ & 0.912 & 0.908 & 0.898 & 0.911 & 0.925 & 0.922 & 0.913 \\
Average of $e_{\text {no-impact }}$ & 0.962 & 0.965 & 0.960 & 0.962 & 0.962 & 0.962 & 0.959 \\
Weighted average & $e_{1}=\mathbf{0 . 8 6 1}$ & $\boldsymbol{e}_{2}=\mathbf{0 . 9 6 3}$ & \multicolumn{2}{c}{$\boldsymbol{e}_{\text {no-impact }}=\mathbf{0 . 8 9 9}$} \\
\hline
\end{tabular}


revenue loss. ${ }^{16}$ The total capital expenditure of the companies that fall short of no impact efficiency accounts for $34 \%$ of the sector investment whereas this figure is about $66 \%$ for networks that obtained or exceeded no impact efficiency. Therefore, the net effect of the new reallocation is an increase in total investments without reducing the average efficiency of the sector.

As discussed above, the outcome of ex-post regulatory treatment of investments through total cost benchmarking is that some firms will lose part of their capital cost while some others recover all their investment and some make above normal profits. For example, the firms that appear to have outperformed the investment efficiency requirement-i.e. their efficiency after investments exceeded the no impact efficiency considerably (the instance of $Q>0$ discussed in Section 3.1) can earn more compared to the no benchmarking case. Under the circumstance that an "investment efficient firm" gains and an "investment inefficient firm" loses, the ex-post regulatory treatment of investment is effective in rewarding efficient and penalising inefficient firms.

However, this might not always be the case as the condition under which benchmarking produces reliable results does not always hold. This is because efficiency, in benchmarking terms, is a relative concept and only reveals information about firm performance in relation to other firms. Thus, the relative efficiency of a firm can also improve when the peer companies are not performing well. For instance, when companies are capital productive and their investments are used and useful, they might move to a higher level of relative efficiency after investments. However, the same can happen when they underinvest, something which gives them the appearance of cost efficiency. Therefore, unless the frontier firms genuinely represent the best practice, the results of benchmarking can be misleading.

The benchmarking limitation regarding investment embraces other cases such as when the firms' investments behaviour is harmonised in the sense that they are in the same phases of their investment cycles. This refers to the case that firms invest in similar periods and in proportion to their total cost levels but beyond their actual need. As the measure of efficiency is relative the firms tend to remain in a relatively similar efficiency position before and after investment. Under this condition, benchmarking can fail to identify the incidence of overinvestment.

The regulator expects that the threat of partial disallowance of capital expenditures built into the regulatory formula leads the firms towards efficient investments. However; the power of the model to detect overinvestments is limited to the case of 'out of phase' investments (i.e. when firms are not in the same investment cycle). Thus, sector-wide 'in phase' or cyclically harmonised overinvestments by the firms are not revealed in the process of benchmarking because the approach is based on between-firms comparisons. This will, in turn, limit the ability of the regulator to effectively address the issue of overinvestment. Harmonised investment behaviour can happen when many firms follow a similar investment policy. For instance, when a regulator guides the investment into a desired direction by, for example, offering a higher return for investments in innovation and particular types of technologies and activities (e.g., Smart Grids).

A parallel argument also holds in the case of harmonised underinvestment. This problem arises when the incentives to invest are not strong enough or the regulation is restrictive which causes firms to reduce their investments. In the short run, this can give the appearance of cost efficiency while, overtime, leading to gradual degradation of the networks and their reliability.

16. In this analysis we ignore the concept of dynamic efficiency hence; we do not take into account the cost effect of investments that takes more than one regulatory period to become realised. This is because our positive analysis is based on the current form of incentive regulation with ex-post regulatory treatment of investments as practiced in Norway and some other countries. 
There are some possible remedies to address the cases of harmonised underinvestment or overinvestment. For instance, the regulator can use the power of incentive $(\lambda)$ in order to influence the investment inefficient firms when there is evidence of overcapitalisation. The higher the power of incentive is the greater possibility of financial loss as a result of investment inefficiency. Thus, a high $\lambda$ causes investment inefficient firms to reduce their investments and consequently improve their efficiency. Also, frontier firms need to follow the same path to maintain their position on the frontier. At present, $\lambda$ is set at $60 \%$ for Norwegian distribution companies. A small increase in $\lambda$ can reduce the net efficiency gains by the firms and create disincentive for investments. On the contrary, a reduction of the power of incentive aligns the revenue of the firm more with its actual cost and increases its propensity to invest. However, the power of incentive is usually set for a long period of time in order to make the investment behaviour of firms predictable and provide a stable regulatory environment. Therefore, the ability of the regulator to modify the power of incentive can be constrained. ${ }^{17}$

In order to avoid underinvestment and deterioration of quality of supply induced by cost reduction incentives incorporated in incentive regulation, regulators adopt either quality performance targets or include the cost of network energy losses and cost of energy not supplied in benchmarking model as in the case of Norway. This is to prevent systematic underinvestment which can endanger network reliability over time. However, the issue is that underinvestment can have an immediate effect on efficiency improvement of the network whereas its impact on network reliability will be realised in the longer run.

Another possible problem of ex-post regulatory treatment of investment using benchmarking is that it can ease the strategic behaviour for trade-off between Capex and Opex ${ }^{18}$ in order to avoid revenue loss from investment inefficiency when firms invest beyond their productive capacity. For instance, as shown in Table 2, investments and other costs are negatively correlated in such a way that a $1 \%$ increase in investment with respect to the mean of the sector can result in $0.92 \%$ reduction of other costs. This in turn raises the regulatory issue of substitution of capital for labour introduced by Averch-Johnson (1962).

The regulatory treatment of investments involves a risk sharing dimension between the utilities and the consumers irrespective of being ex-ante or ex-post. The ex-post regulatory treatment of investment has the merit of being less interventionist. However, this comes at the cost of transferring investment risks to the companies. On the contrary, the ex-ante regulatory model is more interventionist but less risky for the investments of the network companies because risks are mainly transferred to the users of networks.

Thus, it is less likely that firms operating under a pure ex-ante regulatory regime (i.e., no ex-post evaluation of used and useful capital) peruse cost reducing investments as the investment cost is decoupled from their efficiency level. For example, in the UK, under the current regulatory framework for electricity and gas transmission networks, which are a form of ex-ante model (though subject to ex-post efficiency assessment), consumers are exposed to $75 \%$ of the companies "actual cost" (Ofgem, 2010). ${ }^{19}$ Under the ex-post model it is more likely that consumers are exposed to the "efficient cost" of firms however, the implementation of this model has proven to be more complicated that initially perceived.

17. This strategy can have significant side effects such as inducing uncertainty in regulation. Therefore, it needs to be used with strong evidence of persistent or systematic over or underinvestment in the sector.

18. Capital expenditures and operational expenditures.

19. This figure is perceived to be lower for electricity and gas distribution companies (Ofgem, 2010). 
To sum up, the relationship between investment and efficiency under incentive regulation with ex-post regulatory treatment of investment is not straightforward. As efficiency is a relative concept in economics, performance of a firm is not only related to its own behaviour but also to that of other firms. The conditions under which overinvestment can reduce cost efficiency might not always hold. Moreover, it takes time for underinvestment to appear as cost in the form of quality of service deterioration. The Norwegian regulator attempts to incentivise the companies to operate and maintain their networks in an efficient manner and provide a high level of reliability. However, the use of total cost benchmarking does not necessarily lead to the socio-economic efficient level of investments. The implication of these for regulatory framework of network companies is that, there is no ideal measure to address the issue of investment under regulation given the trade-off between the level of intervention and risks of capital cost to the utilities or their consumers. Therefore, the regulator might choose to combine the effective elements of different approaches to balance between the benefits and shortcomings of taking up a particular method. Some previous works which have proposed such new approaches, in the context of transmission grid, include combining the merchant model with benchmark or price regulation models (see Hogan et al., 2010) or the design of network tariffs such as two-part tariffs as in Vogelsang (2001).

\section{CONCLUSIONS}

Contrary to the early years of electricity sector reforms when regulators were mainly concerned with cost efficiency, an emerging and pressing issue is how to ensure sufficient and efficient level of investments in the regulated networks. Over the years, efficiency of the natural monopoly power networks has been improving as a result of incentive regulation. However, the need for significant investments in the coming years combined with the incentives to reduce costs gives rise to new challenges regarding the efficiency and sufficiency of investments in the networks. In this study we analysed the relation between cost efficiency and investments in electricity distribution networks under ex-post regulatory treatment of capital expenditures using the case of Norway.

We introduced the concept of "no impact efficiency" as a revenue-neutral efficiency effect of investments under cost benchmarking which, if achieved, makes the firm "investment efficient" and immune from cost disallowance in the benchmarking process. Also, we estimated the observed efficiency effect of investments in order to compare this with the no impact efficiency and discussed the implication of cost benchmarking for the investment behaviour of distribution companies in Norway.

The results show that the weighted average efficiency gain of the networks from investments is $10 \%$ reflecting the fact that more investment often resulted in higher efficiency. The results suggest that networks that fall short of the no impact efficiency need to reduce their capital expenditure in order to improve their efficiency following investment. On the other hand, firms that outperform the no impact efficiency may wish to increase their investment levels in order to gain from the efficiency they achieved. Overall, the new reallocation of investments increases the total investment of the sector as a whole but without lowering the average efficiency gain of the sector.

At the same time, there are significant variations in efficiency gain following investments at the level of individual companies. Firms with average investment to total cost ratio have gained more efficiency through their investments relative to those with higher or lower than average. Moreover, the efficiency loss following investments is mainly related to the smaller networks. An implication of this for regulatory framework can be that cost reducing incentives have adversely affected the smaller firms leading to lower level of investments and higher operating costs and 
consequently efficiency loss in these firms. Given that average investment levels have been more productive indicates that the incentives should prevent the network utilities from going below or beyond certain levels of capital expenditures.

The relationship between investment and efficiency under incentive regulation is not straight forward. The effectiveness of ex-post regulatory treatment of investments relies on the reliability of benchmarking results which are potentially vulnerable to certain trends and behaviours such as harmonised over- and under-investments. Despite these issues, under the ex-post regulatory treatment of investments, consumers are more likely to be exposed to efficient level of costs compared with the ex-ante model. At the same time, the networks bear a higher investment risk under the ex-post model. Thus, the regulatory treatment of investment always involves an element of risk sharing trade-off between the firms and their consumers.

\section{ACKNOWLEDGMENTS}

The authors are very grateful to Luis Orea and two anonymous referees for valuable comments on this paper. Financial support from the UK ESRC and The Research Council of Norway (Sustainable Grid Development Project-SusGrid) are gratefully acknowledged.

\section{REFERENCES}

Abrate, G., and F. Erbetta (2010). "Efficiency and Patterns of Service Mix in Airport Companies: An Input Distance Function Approach." Transportation Research Part E 46: 693-708. http://dx.doi.org/10.1016/j.tre.2009.12.003.

Ai, C., and D.E.M. Sappington (2002). "The Impact of State Incentive Regulation on the U.S. Telecommunications Industry." Journal of Regulatory Economics 22(2): 107-132. http://dx.doi.org/10.1023/A:1020583427467.

Averch, H., and L.L. Johnson (1962). "Behaviour of the Firm under Regulatory Constraint. “ American Economic Review 52: 1059-69.

Burn, P., and C. Riechmann (2004). "Regulatory Instruments and Investments Behavior.” Utility Policy 12: 211-219. http:// dx.doi.org/10.1596/1813-9450-3292.

Cambini, C., and L. Rondi (2010). "Incentive Regulation and Investment: Evidence from European Energy Utilities." Journal of Regulatory Economics 38: 1-26. http://dx.doi.org/10.1007/s11149-009-9111-6.

Coelli, T.J., and S. Perelman (1996). "Efficiency Measurement, Multiple-Output Technologies and Distance Functions: With Application to European Railways.” CREPP Discussion Paper 96/05, University of Liege.

Coelli, T.J., D.S.P. Rao, C. O’Donnell and G.E. Battese (2005). An Introduction to Efficiency and Productivity Analysis. $2^{\text {nd. }}$ Edition, New York. Springer.

Coelli, T., A. Gautier, S. Perelman and R. Saplacan-Pop (2012). "Estimating the Cost of Improving Quality in Electric Distribution: A Parametric Distance Function Approach.” CREPP working paper No. 2012/02.

Crew, M.A. and P.R. Kleindorfer (1996). "Incentive Regulation in the United Kingdom and The United States: Some Lessons." Journal of Regulatory Economics 9(3): 211-225. http://dx.doi.org/10.1007/BF00133474.

Das, A. and S.C. Kumbhakar (2012). "Productivity and Efficiency Dynamics in Indian banking: An Input Distance Function Approach Incorporating Quality of Inputs and Outputs." Journal of Applied Econometrics 27(2): 205-234. http:// dx.doi.org/10.1002/jae.1183.

Dixit, A., R. Pindyck (1994). Investment under Uncertainty. Princeton University Press, Princeton, NJ.

Färe, R. and C.A.K. Lovell (1978). "Measuring the Technical Efficiency of Production." Journal of Economic Theory 19: 150-62. http://dx.doi.org/10.1016/0022-0531(78)90060-1.

Gal-Or, E.H. and M. Spiro (1992). "Regulatory Regimes in the Electric Power Industry: Implications for Capacity." Journal of Regulatory Economics 4: 263-278. http://dx.doi.org/10.1007/BF00133623.

Giannakis, D., T. Jamasb and M. Pollitt (2005). "Benchmarking and Incentive Regulation of Quality of Service: An Application to the UK Electricity Distribution Networks." Energy Policy 33(17): 2256-2271. http://dx.doi.org/10.1016/ j.enpol.2004.04.021.

Greene, W.H. (2008). "The Econometric Approach to Efficiency Analysis," in Fried, O.H., C.A.K. Lovell and S.S. Schmidt. eds., The Measurement of Productive Efficiency and Productivity Growth. 2008. Oxford University Press: New York. 
Greenstein, S., S. McMaster and P. Spiller (1995). "The effect of Incentive Regulation on Infrastructure Modernization: Local Exchange Companies' Deployment of Digital Technology.” Journal of Economics and Management Strategy 4(2): 187-236. http://dx.doi.org/10.1111/j.1430-9134.1995.00187.x.

Growitsch, C., T. Jamasb and H. Wetzel (2012). "Efficiency Effects of Observed and Unobserved Heterogeneity: Experience from Norwegian Electricity Distribution.” Energy Economics 34: 542-548. http://dx.doi.org/10.1016/j.eneco.2011.10.013.

Helm, D. and D. Thompson (1991). "Privatized Transport Infrastructure and Incentives to Invest." Journal of Transport Economics and Policy 15(1): 231-246.

Hess, B. and A. Cullmann (2007). "Efficiency Analysis of East and West German Electricity Distribution Companies—Do the "Ossis” Really Beat the "Wessis"?” Utilities Policy 15(3): 206-214. http://dx.doi.org/10.1016/j.jup.2007.03.002.

Hogan, W., J. Rosellón and I. Vogelsang (2010). “Toward a Combined Merchant-Regulatory Mechanism for Electricity Transmission Expansion.” Journal of regulatory Economics 38:113-143. http://dx.doi.org/10.1007/s11149-010-9123-2.

Jamasb, T., L. Orea and M.G. Pollitt (2012). "Estimating Marginal Cost of Quality Improvements: The Case of the UK Electricity Distribution Companies." Energy Economics 34(5): 1498-1506. http://dx.doi.org/10.1016/j.eneco. 2012.06.022.

Joskow, P.L. (2008). "Incentive Regulation and Its Application to Electricity Networks." Review of Network Economics 7(4): 547-560. http://dx.doi.org/10.2202/1446-9022.1161.

Joskow, P.L. (2005). "Incentive Regulation in Theory and Practice: Electricity Distribution and Transmission Networks." EPRG Working Paper 05/11. University of Cambridge.

Kumbhakar, S.C. and C.A.K. Lovell (2000). Stochastic Frontier Analysis. Cambridge University Press, Cambridge. http:// dx.doi.org/10.1017/CBO9781139174411.

Lyon, T. and J. Mayo (2005). "Regulatory Opportunism and Investment Behavior: Evidence from the U.S. Electric Utility Industry." Rand Journal of Economics 36(3): 628-644.

Markou, E., and C. Waddams Price (1999). "UK Utilities: Past Reform and Current Proposals." Annals of Public and Cooperative Economics 70: 371-416. http://dx.doi.org/10.1111/1467-8292.00118.

Miguéis, V.L., AS. Camanho, E. Bjørndal and M. Bjørndal (2011). "Productivity Change and Innovation in Norwegian Electricity Distribution Companies." Journal of the Operational Research Society 63(7): 982-990. http://dx.doi.org/ 10.1057/jors.2011.82.

Nagel, T. and M. Rammerstorfer (2008). “Investment Decisions under Market Concentration and Price Regulation.” Working Paper Series, Vienna University of Economics and Business Administration. Available at: http://ssrn.com/abstract $=1009123$.

Newbery, D. (2002). "Rate-of-return Regulation versus Price Regulation for Public Utilities." in Newman, E. eds., The New Palgrave Dictionary of Economics and the Law: 3. Palgrave McMillan.

NordREG (2011). "Economic Regulation of Electricity Grids in Nordic Countries." Nordic Energy Regulator, Report 7/ 2011, Copenhagen; Available online at: https://www.nordicenergyregulators.org/ publications/publications-2011/.

NVE (2007). "Report on Regulation and the Electricity Market Norway." Norwegian Water Resources and Energy Directorate (NVE). Oslo, Norway. Available online: http://www.energy-regulators.eu/portal/page/portal/EER_HOME/EER_ PUBLICATIONS/NATIONAL_REPORTS/NR_2007/NR_En/E07_NR_Norway-EN.doc.

NVE (2008). "Report on Regulation and the Electricity Market Norway." Norwegian Water Resources and Energy Directorate (NVE), Oslo. Available online at: http://www.energy-regulators.eu/portal/page/ portal/EER_HOME/EER_ PUBLICATIONS/ ATIONAL_REPORTS/ National\%20reporting\%202008/ NR_En/E08_NR_Norway-EN.pdf.

NVE (2010). “Annual Report 2010: The Norwegian Energy Regulator.” Norwegian Water Resources and Energy Directorate (NVE), Oslo, Available online at: http://www.nve.no/Global/Publikasjoner/ Publikasjoner\%202011/Diverse\%202011/ NVE_annual_report_2010.pdf.

NVE (2011). "Report on Regulation and the Electricity Market Norway." Norwegian Water Resources and Energy Directorate (NVE), Oslo, Available online: http://www.energy- regulators.eu/portal/page/portal/EER_HOME/EER_ PUBLICATIONS/ NATIONAL_REPORTS/ National\%20Reporting\%202011/NR_En/ C11_NR_Norway-EN.pdf

Ofgem (2010). "RPI-X@20 Emerging Thinking Consultation Document- Alternative Ex Ante and Ex Post Regulatory Frameworks." Supporting paper, Office of Gas and Electricity Markets, London. https://www.ofgem.gov.uk/ofgem-publications/51950/et-alternatives.pdf.

Perelman, S. and D. Santin (2005). "On the Generation of a Regular Multi-Input Multi-Output Technology using Parametric Output Distance Functions.” CREPP Working Papers 0507, Centre de Recherche en Economie Publique et de la Population (CREPP) (Research Center on Public and Population Economics) HEC-Management School, University of Liège.

Roques, F. and N. Savva (2009). "Investment under Uncertainty with Price Ceilings in Oligopolies." Journal of Economic Dynamics and Control 33: 507-524. http://dx.doi.org/10.1016/j.jedc.2008.07.002.

Rovizzi, L., and D. Thompson (1995). “The Regulation of Product Quality in the Public Utilities.” In: Bishop, M., J. Kay and C. Mayer, eds., The Regulatory Challenge. Oxford University Press. 
Sauer, J., K. Frohberg and H. Hockmann (2006). "Stochastic Efficiency Measurement: The Curse of Theoretical Consistency." Journal of Applied Economics 9(1): 139-165.

Tovar, B., F.J. Ramos-Real and E.F. de Almeida (2011). "Firm Size and Productivity: Evidence from the Electricity Distribution Industry in Brazil.” Energy Policy 39(2): 826-833. http://dx.doi.org/10.1016/j.enpol.2010.11.001.

Vogelsang, I. (2001). "Price Regulation for Independent Transmission Companies." Journal of Regulatory Economics 20(2):141-165. http://dx.doi.org/10.1023/A:1011103328722.

Vogelsang, I. (2002). "Incentive Regulation and Competition in Public Utility Markets: A 20-Year Perspective." Journal of Regulatory Economics 22(1): 5-27. http://dx.doi.org/10.1023/A:1019992018453.

von Hirschhausen, C. (2008), "Infrastructure, Regulation, Investment and Security of Supply: A Case Study of the Restructured US Natural Gas Market." Utilities Policy 16: 1-10. http://dx.doi.org/10.1016/j.jup.2007.08.001.

Waddams Price, C., B. Brigham and L. Fitzgerald (2002). "Service Quality in Regulated Monopolies.” CCR Working Paper CCR 02-4. Centre for Competition and Regulation. University of East Anglia, Norwich.

\section{APPENDIX}

\section{Table A1: Regularity Conditions (monotonicity)}

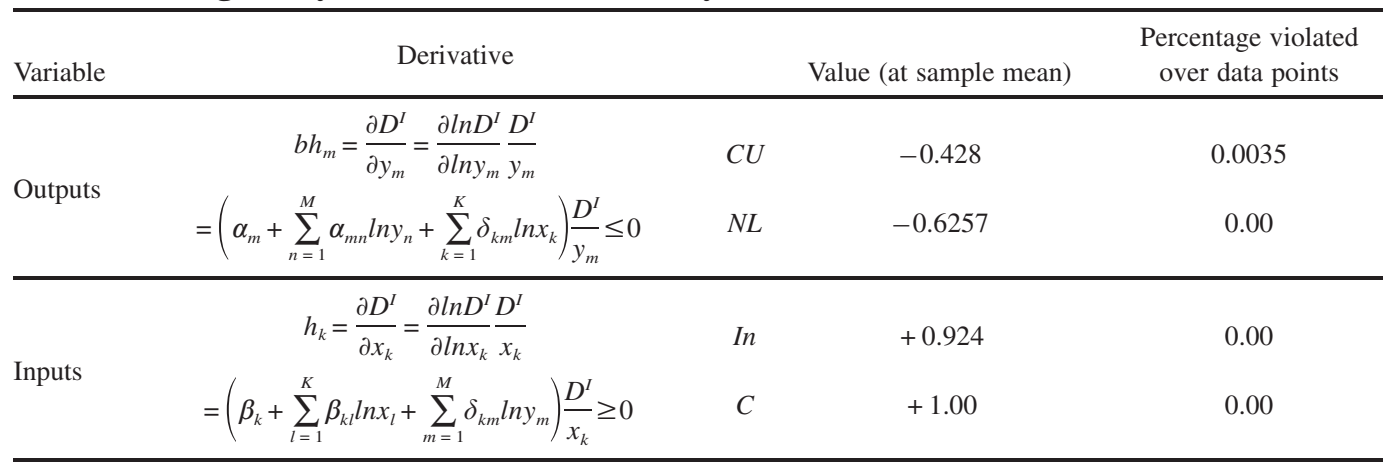

Table A2: Regularity Conditions (concavity)

\begin{tabular}{|c|c|c|}
\hline Curvature and corresponding matrix & $\begin{array}{l}\text { Value at sample mean } \\
\qquad(K=M=2)\end{array}$ & $\begin{array}{c}\text { Percentage with } \\
\text { correct curvature over } \\
\text { data points }\end{array}$ \\
\hline $\begin{array}{c}\text { Quasi-concave(Outputs) } \\
B H=\left[\begin{array}{cccc}0 & b h_{1} & \ldots & b h_{M} \\
b h_{1} & b h_{11} & \ldots & b h_{1 M} \\
\vdots & \vdots & \vdots & \vdots \\
b h_{M} & b h_{1 M} & \ldots & b h_{M M}\end{array}\right]\end{array}$ & $\begin{array}{l}{\left[\begin{array}{ccc}0 & -0.530 & -0.711 \\
-0.530 & 0.271 & 0.175 \\
-0.711 & 0.175 & 0.564\end{array}\right]} \\
\text { Definiteness at sample mean: Indefinite }\end{array}$ & $18.7 \%$ \\
\hline $\begin{array}{c}\text { Concave(Inputs) } \\
H=\left[\begin{array}{cccc}h_{11} & h_{12} & \ldots & h_{1 K} \\
h_{21} & h_{22} & \ldots & h_{2 K} \\
\vdots & \vdots & \vdots & \vdots \\
h_{K 1} & h_{K 2} & \ldots & h_{K K}\end{array}\right]\end{array}$ & $\begin{array}{l}{\left[\begin{array}{cc}-0.936 & 0 \\
0 & -1.101\end{array}\right]} \\
\text { Definiteness at sample mean: Negative } \\
\text { definite }\end{array}$ & $100 \%$ \\
\hline
\end{tabular}




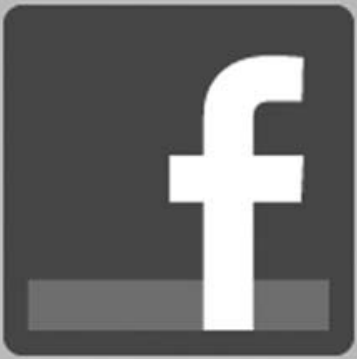

Connect with

\section{IAEE}

on facebook

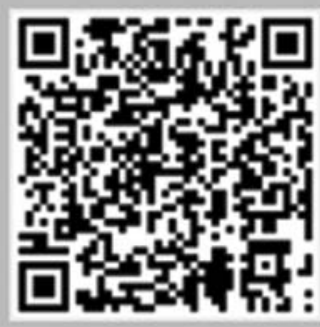

